\title{
SOCIABILIDADES NEGRAS NA PARAÍBA ESCRAVISTA: SOCIEDADE, ECONOMIA E RESISTÊNCIAS
}

Solange P. Rocha ${ }^{1}$

Matheus S. Guimarães ${ }^{2}$

Resumo: Este artigo tem como objetivo apresentar uma síntese de como estava organizada a sociedade escravista na Paraíba entre os séculos XVIII e XIX. Os recentes estudos sobre escravidão têm se expandido e permitido identificar alguns aspectos relacionados ao tráfico de pessoas escravizadas, às experiências de formação de famílias cativas e às comunidades formadas por fugitivas e fugitivos do cativeiro. Neste trabalho destacamos, então, traços sociodemográficos e econômicos, assim como algumas experiências de vida e resistência construídas pelos africanos e seus descendentes no território que, a partir do século XVI, passou a ser designado de Paraíba. Para isso, utilizamos diversas fontes, como documentos avulsos do Arquivo Histórico Ultramarino (AHU/PT/BR) digitalizados pelo Projeto Resgate, registros de batismo da Freguesia de Nossa Senhora das Neves, testamentos e inventários no Livro de Notas da cidade da Paraíba, além dos dados sistematizados pelo Transatlantic Slave Trade Database (TSTD) e a bibliografia referente ao tema. Assim, expusemos algumas frestas de liberdade desse grupo social e suas relações sociais em contexto adverso.

Palavras-chave: Escravidão; Paraíba; séculos XVIII e XIX; resistência; população negra

\section{BLACK SOCIABILITIES IN SLAVE PARAÍBA: SOCIETY, ECONOMY AND RESISTANCE}

Abstract: This article aims to present a synthesis of how the slave society in Paraíba was organized between the 18th and 19th centuries. Recent slavery studies have expanded and allowed to identify some aspects related to trafficking in enslaved people,

\footnotetext{
${ }^{1}$ Professora da Universidade Federal da Paraíba/UFPB. Integra o Núcleo de Estudos e Pesquisas Afrobrasileiros e Indígenas/NEABI na mesma universidade. Este artigo faz parte de um projeto de pesquisa maior desenvolvido no Programa de Pós-Graduação em História na UFPB. ORCID: https://orcid.org/0000-0002-3255-1873 E-mail: banto20@gmail.com

${ }^{2}$ Doutorando em História na Universidade Federal de Pernambuco e Professor da Rede Municipal de João Pessoa/Paraíba. ORCID: https://orcid.org/0000-0001-5756-1958 mail: guimaraesmatheuss@gmail.com
}

Revista da ABPN • v. 12, n. Ed. Especial - Caderno Temático: "Africanos, escravizados, libertos biografias, imagens e experiências atlânticas” • agosto de 2020, p. $197-222$ 
to the experiences of forming captive families and to communities formed by fugitives and fugitives from captivity. In this work, we highlight socio-demographic and economic traits, as well as some experiences of life and resistance built by Africans and their descendants in the territory that, from the 16th century on, became known as Paraíba. For this, we used several sources, such as separate documents from the Overseas Historical Archive (AHU/PT/BR) digitized by the Rescue Project, baptism records from the parish of Nossa Senhora das Neves, wills and inventories in the Note Book of the city of Paraíba, in addition to the data systematized by the Transatlantic Slave Trade Database (TSTD) and the bibliography on the topic. Thus, we exposed some cracks of freedom of this social group and its sociais relations in an adverse context.

Keywords: Slavery; Paraíba; 18th and 19th centuries; resistance; black population

\section{SOCIABILIDADES NEGRAS EN ESCLAVO PARAÍBA: SOCIEDAD, ECONOMÍA Y RESISTENCIA}

Resumen: Este artículo tiene como objetivo presentar una síntesis de cómo se organizó la sociedad de esclavos en Paraíba entre los siglos XVIII y XIX. Los estudios recientes sobre la esclavitud se han expandido y han permitido identificar algunos aspectos relacionados con el tráfico de personas esclavizadas, las experiencias de formar familias cautivas y las comunidades formadas por fugitivos y fugitivos del cautiverio. En este trabajo, destacamos los rasgos sociodemográficos y económicos, así como algunas experiencias de vida y resistencia construidas por los africanos y sus descendientes en el territorio que, a partir del siglo XVI, se conoció como Paraíba. Para esto, utilizamos varias fuentes, como documentos separados del Archivo Histórico de Ultramar (AHU / PT / BR) digitalizados por el Proyecto de Rescate, registros de bautismo de la parroquia de Nossa Senhora das Neves, testamentos e inventarios en el Cuaderno de notas de la ciudad de Paraíba, además de los datos sistematizados por la Base de Datos Transatlántica de Comercio de Esclavos (TSTD) y la bibliografía sobre el tema. Así, expusimos algunas grietas de libertad de este grupo social y sus relaciones sociales en un contexto adverso.

Palabras llave: esclavitud; Paraíba Siglos XVIII y XIX; resistencia; población negra

\section{SOCIÉTÉS NOIRES DE SLAVE PARAIIBA: SOCIÉTÉ, ÉCONOMIE ET RÉSISTANCE}

Résumé: Cet article vise à présenter la société esclavagiste de Paraíba entre le XVIIIe et le XIXe siècle et certaines formes de résistance des femmes et des hommes réduits en esclavage. Des études récentes sur l'esclavage se sont développées et ont permis d'identifier certains aspects liés à la traite des personnes réduites en esclavage, aux expériences de formation de familles captives et aux communautés formées par les fugitifs de captivité. Dans ce travail, nous mettons en évidence les traits sociodémographiques et économiques, ainsi que certaines expériences de vie et de résistance construites par les Africains et leurs descendants sur le territoire qui, à partir du 16ème

Revista da ABPN • v. 12, n. Ed. Especial - Caderno Temático: "Africanos, escravizados, libertos biografias, imagens e experiências atlânticas” • agosto de 2020, p. $197-222$ 
siècle, est devenu Paraíba. Pour cela, nous avons utilisé plusieurs sources, telles que des documents séparés des archives historiques d'outre-mer (AHU/PT/BR) numérisés par le projet de sauvetage, des registres de baptême de la paroisse de Nossa Senhora das Neves, des testaments et des inventaires trouvés dans les cahiers de la ville de Paraíba, en plus de données systématisées par la base de données sur le commerce transatlantique des esclaves (TSTD) et la bibliographie sur le sujet. Ainsi, nous avons exposé quelques fissures de liberté de ce groupe social et de ses relations sociales dans un contexte esclavagiste.

Mots clés: Esclavage; Paraíba; 18e et 19e siècles; la résistance; population noire.

\section{INTRODUÇÃO}

Paulina, uma crioula escravizada, foi batizada na Igreja Matriz da cidade da Paraíba do Norte em agosto de 1847. Na ocasião ela tinha entre dez e quinze anos e corria "risco de vida". O batismo era/é o principal sacramento da Igreja Católica e no século XIX era uma prática não só religiosa, mas também social de extrema importância, pois laços eram formados ou consolidados, era um documento para confirmar a relação com a comunidade e também a condição jurídica das pessoas. A sua mãe, Maria, era uma mulher preta e escolheu para ser padrinho de Paulina um homem africano chamado Francisco Gangá e para madrinha Antonia Corrêa. ${ }^{3}$

Do passado de Francisco Gangá legamos alguns vestígios históricos que nos informam sobre a sua ascensão social - de escravizado se tornou um liberto e possuidor de imóveis na capital da Paraíba -, da sua influência social e liderança na comunidade de pessoas negras da Paraíba oitocentista - foi padrinho de crianças e adultos negros; escravizados e livres; de africanas, crioulos e mestiços -, não sendo aleatória, portanto, a sua escolha para ser o "protetor" de Paulina. Além disso, o fato de Maria ser classificada como "preta", indicativo de ser uma escravizada africana, era uma maneira de estabelecer ou manter laços com o "malungo" Gangá, que recebeu o nome cristão de Francisco em território da diáspora africana.

\footnotetext{
${ }^{3} \mathrm{O}$ assento de batismo de Maria encontra-se no livro de batismo da freguesia Nossa Senhora das Neves (1846-1850, fl, 74), depositado no acervo do Arquivo Eclesiástico da Arquidiocese da Paraíba/AEAPB. No Brasil escravista do século XIX, as diversas denominações de cores estavam associadas às origens e status social. Termos como "preto", "crioulo", "pardo", "cabra", "semibranco", entre outros diziam respeito a como a sociedade via essas pessoas e as classificavam racialmente.
}

Revista da ABPN • v. 12, n. Ed. Especial - Caderno Temático: "Africanos, escravizados, libertos biografias, imagens e experiências atlânticas” • agosto de 2020, p. 197-222 
Não temos como saber quando Francisco Gangá chegou ao Brasil, mas - devido ao seu nome e por ser um homem liberto - possivelmente veio da África CentroOcidental e já estava há alguns anos na Paraíba. Gangá também tinha relações com pessoas da elite - a exemplo do comerciante inglês Carlos Holmes -, participava da Irmandade do Rosário dos Pretos, importante espaço de convivência. Com isso, também se aproximava de pessoas negras libertas e escravizadas, como Maria e Paulina. Outras duas mulheres chegaram de Angola na Paraíba e tiveram como padrinho Francisco Gangá. Eram Margarida (preta gentio de Angola) e Josefa (preta de Angola), que foram batizadas alguns dias antes de Paulina.

Francisco era casado com Cosma Correia, também preta e liberta, mas num assento de batismo são ditos como "pretos livres desta freguesia". Em tal registro, datado de 01 de setembro de 1839, o casal batizou o bebê Manoel (um mês de nascido), filho de Rita, uma crioula livre. ${ }^{4}$ Não deixaram filho, porém conseguiram estabelecer uma ampla rede de amizades, parentesco social e solidariedade em uma sociedade escravista, na qual foram submetidos à violência da travessia atlântica e do trabalho forçado, mas conseguiram sua liberdade, estabeleceram e mantiveram variadas interações sociais. $^{5}$

O termo ganga (ou n'ganga ou nganga), que referencia Francisco, remete-nos à cultura religiosa dos povos bantos, em específico dos territórios de Congo e Angola, onde tal denominação referia-se ao indivíduo que cuidava de "assuntos religiosos", o "feiticeiro negro" (CALAINHO, 2001, p. 160) e eram considerados seres com "poderes da terra e das águas e recebiam os espíritos ligados à dimensão do cariapemba", ou seja, uma divindade com capacidade de proteger e destruir, conforme Silva (1992, p. 493). Recentemente, Lopes (2006, p. 107) reitera e amplia a compreensão sobre as funções do Nganga nas comunidades dos povos bantos, pois tal designação referia-se ao "feiticeiro", mas também ao "mestre, o técnico, alguém competente numa atividade". A partir dessas referências, entendemos que Francisco Gangá dispunha de reconhecimento

\footnotetext{
${ }^{4}$ Conforme consta no livro de batismo da freguesia Nossa Senhora das Neves (1833-1841, fl. 130), no acervo AEAPB.

${ }^{5} \mathrm{O}$ testamento do casal Francisco Gangá e Cosma Correia encontra-se no Livro de Notas da Cidade da Parahyba (1841-1846), no Arquivo do Instituto Histórico e Geográfico Paraibano/AIHGPB, respectivamente. A trajetória de Gangá foi abordada por Rocha (2009) e Guimarães (2018). No texto atual, inserimos novas abordagens.
}

Revista da ABPN • v. 12, n. Ed. Especial - Caderno Temático: "Africanos, escravizados, libertos biografias, imagens e experiências atlânticas” • agosto de 2020, p. $197-222$ 
da comunidade negra da capital da Paraíba e conectou universos sociais diferentes, posto que, como dito anteriormente, ele circulava entre sujeitos de diferentes condições jurídicas, ou mesmo apoiando famílias negras em diferentes momentos das suas vidas na tumultuada segunda metade do século XIX.

Foram muitos os sujeitos negros que deixaram indícios de suas vidas no Brasil escravista (FARIAS et al, 2006. Lima; Silva, 2018). Destacamos alguns que viveram na Paraíba Oitocentista, como Francisco Gangá, Cosma Correia e seus afilhados e afilhadas, comadres e compadres. Milhares vieram de navios da África, submetidos às violências e arbitrariedades do tráfico. Outras nasceram na referida capitania/província e vivenciaram diferentes experiências de opressão em uma sociedade escravista. No limiar tênue entre escravidão e liberdade, essas pessoas tentaram constantemente construir e reconstruir suas vidas em uma região periférica economicamente, que foi construída a partir, principalmente, da exploração do trabalho forçado de povos indígenas e da população negra (MEDEIROS, 1999; ROCHA, 2009; ROCHA e GUIMARÃES, 2015; GUIMARÃES, 2018).

O objetivo deste artigo é apresentar um panorama da sociedade escravista da Paraíba entre os séculos XVIII e XIX, destacando algumas experiências de vida e resistência da população negra. A Paraíba teve sua formação histórica e inserção no sistema-mundo moderno a partir de uma relação complexa com Pernambuco. Isso fez com que, mesmo diante de características gerais da escravidão, presentes em todo o Brasil, a elite paraibana buscasse alguns caminhos específicos para o enfrentamento de suas crises cíclicas desde o período colonial que permaneceram no Oitocentos, conforme discursos presentes nas fontes oficiais sobre o referido território.

Este artigo está dividido em três partes. Na primeira, dedicamos-nos a apresentar um quadro geral socioeconômico da Paraíba entre os séculos XVIII e XIX. Informações referentes à produção do açúcar e algodão estão associadas ao quantitativo de entrada de africanos e a uma análise sobre a demografia. Dessa maneira, conseguimos ter uma noção mais ampla da população negra (escravizada, liberta e livre). Em um segundo momento, partimos para o estudo de uma experiência específica: Baldoína, mulher negra escravizada e mãe de família. Com isso, pretendemos mostrar como se davam as vivências dessas pessoas na Paraíba. Por fim, trazemos casos de uma forma bem

Revista da ABPN • v. 12, n. Ed. Especial - Caderno Temático: "Africanos, escravizados, libertos biografias, imagens e experiências atlânticas" • agosto de 2020, p. $197-222$ 
conhecida de resistência contra a opressão escravista, mas que requer mais estudos: os redutos de escravizados fugitivos, também designados de mocambos e quilombos no Brasil (MOURA, 1972; REIS; GOMES, 1996). Como era comum às regiões escravistas, vários foram os quilombos que se organizaram na circunvizinhança das regiões ditas produtivas e com as quais os quilombolas, em geral, mantinham trocas econômicas e conexões sociais. A narrativa histórica foi baseada em fontes diversas, como alguns documentos sistematizados pela obra de Irineu Pinto (1977), o acervo disponibilizado pelo Projeto Resgate do Arquivo Histórico Ultramarino de Portugal referentes à Paraíba, os números presentes no banco de dados do Transatlantic Slave Trade Database, registros de batismos e testamentos do século XIX, além da bibliografia específica sobre o tema.

\section{A PARAÍBA: TRÁFICO E ESCRAVIDÃO}

A escravidão no Brasil foi uma prática sistemática e generalizada e se estabeleceu de forma profunda em todas as regiões, chegando a ser uma instituição que definiu, inclusive, a unidade territorial do país. Devemos lembrar que, apesar de ter características gerais, havia importantes diferenças e especificidades regionais. Nesse sentido, cabe-nos aqui refletir o caso da sociedade escravista numa província do "norte" do Brasil, a Paraíba. ${ }^{6}$

Refletir acerca da experiência escravista nos remete à dinâmica econômica e as formas como cada região interagia com a economia mundial. Ora, aquelas capitanias/províncias com grande inserção na economia atlântica, demandavam mais escravos africanos. O caso da Paraíba foi diferente. Apesar de ser parte do mundo atlântico, desde a sua formação manteve uma forte dependência em relação ao território ao sul, ou seja, Pernambuco, que em 1574 iniciou a sua expansão territorial e econômica tendo como duplo objetivo: subjugar os povos indígenas que resistiam ao processo de colonização e ampliar os engenhos de açúcar para atender o mercado europeu (GONÇALVES, 2007). Em se tratando do escravismo na Paraíba, temos alguns traços

\footnotetext{
${ }^{6}$ A atual divisão regional do Brasil se construiu no século XX. Até o Oitocentos, o país era dividido, basicamente, entre Norte e Sul.
}

Revista da ABPN • v. 12, n. Ed. Especial - Caderno Temático: "Africanos, escravizados, libertos biografias, imagens e experiências atlânticas” • agosto de 2020, p. $197-222$ 
específicos de tal território e também de outras capitanias/províncias que estiveram subordinadas à economia de Pernambuco. Podemos destacar, por exemplo, como se dava o comércio dos africanos que foram escravizados em terras da Paraíba, Rio Grande do Norte e Ceará, que realizaram poucos contatos diretos com a África Atlântica para negociar e traficar "almas" para serem exploradas em seus territórios. Em geral, dependiam do comércio diretamente com os negociantes de Pernambuco (LOPES, 2008; GUIMARÃES, 2018).

Em relação ao século XVIII, este período foi bastante conturbado para as capitanias do Norte. Diante de uma profunda crise na produção açucareira, na perspectiva da classe senhorial, a capitania em tela passou por dificuldades que agravavam a situação econômica e política. Dentre elas, podemos destacar, em primeiro lugar, as décadas iniciais após as guerras de "expulsão" dos holandeses do território das capitanias do Norte que passaram por reorganização das áreas de produção do açúcar, em razão das lavouras e engenhos destruídos, escravizados fugidos, disputas pela retomada das propriedades de terras e engenhos, perseguições aos povos indígenas etc. Em segundo lugar, destacamos o incremento da concorrência no mercado açucareiro, pois as Antilhas também começaram a produzir, quebrando o monopólio construído por Portugal, o que levou a fortes mudanças nos preços desta mercadoria. Associado a isso, juntamente com a descoberta de ouro nas minas no final do século XVII, houve um aumento dos preços de africanos que foram escravizados, além de uma migração de pessoas para as capitanias do Centro-Sul, atraídas pela economia de mineração. ${ }^{7}$

Até o início do século XVII, nas primeiras décadas da colonização do território, essa capitania foi uma grande produtora de açúcar, ficando dependente desta mercadoria que atendia o mercado europeu até o início do século XX. ${ }^{8}$ Contudo, sua produção era inferior a de Pernambuco, terras dos indígenas caetés, que foi transformada em

\footnotetext{
${ }^{7}$ Sobre a situação econômica de Pernambuco e Paraíba, em especial, a produção do açúcar, sugerimos a leitura de Mello (1995, 2001), Lopes (2008), Oliveira (2007) e Menezes (2005).

${ }^{8}$ No decorrer do século XIX, a economia açucareira perdeu espaço para a produção algodoeira, que se transformou em uma importante fonte de riqueza. Contudo, a produção do açúcar permaneceu, alterando seu processo produtivo e se industrializando ao longo do tempo. Os engenhos se transformaram em usinas na virada do século XIX para o XX. Até o final do século XX, a economia da Paraíba ainda apresentava bons números de produção de açúcar. Para mais detalhes da economia da Paraíba nesse período, ver Fernandes e Amorim (1999).
}

Revista da ABPN • v. 12, n. Ed. Especial - Caderno Temático: "Africanos, escravizados, libertos biografias, imagens e experiências atlânticas” • agosto de 2020, p. $197-222$ 
capitania sob administração de Duarte Coelho (1534/35), um núcleo central do governo português colonial, que no pós-1822 manteve tal condição (RUSSEL-WOOD, 1998), e que no Seiscentos apresentava cerca de 200 engenhos de açúcar. A Paraíba, por sua vez, detinha, no início do século XVIII, cerca de 20 engenhos, chegando em 1851 com 159 engenhos. ${ }^{9}$ Além da economia canavieira, havia a criação de gado e produção de subsitência para os moradores que, gradativamente, apossavam-se do território de povos indígenas. As áreas do litoral passaram a ser formadas por verdes canaviais, que geraram muitas riquezas aos luso-brasileiros e amargor aos povos subordinados, indígenas e africanos, mas que criaram variadas estratégias para afirmação com seres humanos e resistências ao projeto colonial e imperial desenvolvido pelos colonizadores.

Outro aspecto diz respeito ao acesso às rotas de circulação de mercadorias. Ora, a produção e a venda fazem parte de um mesmo processo. Produzia-se açúcar para vender no mercado europeu. Para isso, era necessário ter acesso aos circuitos mercantis existentes. A coroa portuguesa, desde meados do século XVII, por questões de segurança e maior controle sobre o que era produzido, determinou a existência de um regime de frotas. ${ }^{10}$ É constante na documentação as dificuldades dos produtores da Paraíba em acessar as frotas, tornando o açúcar de ruim qualidade, pois poderia ocorrer atrasos na circulação dos navios e, com isso, prejudicar o escoamento do açúcar. $\mathrm{Na}$ década de 1690 já se reclamava dessa situação, ao informar que havia "falta de embarcações nesse porto [da Paraíba] para dela embarcarem os açúcares que se fabricam ou se poderem navegar a tempo conveniente para o Recife" (Carta Régia sobre o açúcar apud PINTO, 1977, p. 85). Essas reclamações permanecem por décadas. Diante de todas essas condições, em geral, no decorrer no século XVIII, a situação da Paraíba era de "letargia profunda, em que a precariedade era a regra" (MENEZES, 2005, p.75).

\footnotetext{
${ }^{9}$ Sobre os números de engenhos, consultar Galliza (1979), Oliveira (2007); Nascimento Filho (2006, p. 31) e Santana (1990).

${ }^{10} \mathrm{O}$ sistema de frotas (ou de comboios) estabelecia que as mercadorias produzidas no Brasil deveriam seguir para Portugal a partir de um conjunto de embarcações, incluindo uma específica para a guerra, que deveria sair dos portos de Rio de Janeiro, Salvador e Recife em um determinado período do ano. A produção da Paraíba, então, deveria ser encaminhada para Recife e de lá partir para a Europa. Essa dinâmica acabou gerando conflitos e dificuldades para os senhores de engenho e lavradores de cana.
}

Revista da ABPN • v. 12, n. Ed. Especial - Caderno Temático: "Africanos, escravizados, libertos biografias, imagens e experiências atlânticas” • agosto de 2020, p. $197-222$ 
Tais dificuldades econômicas levaram, em meados do século XVIII, a Paraíba a ser anexada a Pernambuco, tornando a situação econômica da capitania ainda mais difícil. A autonomia política veio apenas no século XIX, mas as dificuldades e dependência econômica permaneceram, em maior ou menor grau, no decorrer do Oitocentos.

Essa condição econômica de constantes dificuldades não significou ausência de escravos. Ao contrário. Estes eram fundamentais para o funcionamento dessa economia e sociedade. Isso era muito evidente para os senhores, lavradores e autoridades régias. Durante o século XVIII, dentre as capitanias/províncias do Norte, a Paraíba ficava atrás apenas de Pernambuco na proporção de escravos. ${ }^{11}$ Essa tendência permaneceu durante o século XIX, como veremos mais adiante. O funcionamento daquela sociedade estava baseado na escravidão. Dessa forma, os senhores de engenho tentaram se utilizar da mão de obra indígena, em decorrência de complicações econômicas. No final do século XVII, por exemplo, os senhores de engenho e lavradores de cana estavam fazendo o levantamento do número das aldeias, pois diante das dificuldades em comprar escravos, poderiam se utilizar da mão de obra indígena (AHU_CU_014, Cx. 1, D. 95, $7 / 10 / 1675) .^{12}$

Contudo, o traço marcante da escravidão na Paraíba permaneceu tendo na escravidão africana uma importante fonte ou ainda de seus descendentes nascidos no Brasil. No início da década de 1710, o capitão-mor da capitania, João da Maia da Gama, informava que a única solução econômica seria importar escravos africanos (AHU_CU_014, Cx. 5, D. 360, 08/06/1717). O mesmo repetia João de Abreu Castelo Branco, na década seguinte. ${ }^{13}$ Os senhores, para conseguirem ter acesso a essas pessoas escravizadas, pediam isenções à Coroa constantemente até o início do século XIX. ${ }^{14}$

\footnotetext{
${ }^{11}$ Dados demográficos foram sistematizados por Ribeiro Júnior (2004, p.72).

12 Anos depois começam as guerras no sertão das capitanias do Norte que, além de atender aos interesses de expansão territorial da conquista portuguesa, também respondia às demandas por mais mão de obra dos senhores. Sobre essas guerras, consultar Puntoni (2002). No caso da Paraíba, a violência dessas entradas contras os povos indígenas chegaram a espantar as autoridades régias, principalmente, as expedições de Teodósio Oliveira Ledo, que matava "a sangue frio os índio" (PINTO, 1977, p. 93). Consultar também AHU_CU_014, Cx. 3, D. 226, 03/09/1699.

${ }^{13}$ Dizia ele, em 1722 que um dos males econômicos da Paraíba estava na "dificuldade de escravos da Costa da Mina” (AHU_CU_014, Cx. 5, D392, 1722).
}

Revista da ABPN • v. 12, n. Ed. Especial - Caderno Temático: "Africanos, escravizados, libertos biografias, imagens e experiências atlânticas” • agosto de 2020, p. 197-222 
Essa quantidade significativa de escravos era composta de pessoas negras vindas da África e nascidas no Brasil. Como a capitania/província da Paraíba não tinha um porto muito movimentado, tornou-se difícil identificar a circulação existente em sua alfândega. Temos poucos registros de entradas e saídas de navios. Contudo, pela documentação dispersa, sabemos que, apesar da forte influência de Pernambuco, houve participação de moradores da Paraíba no comércio atlântico de escravos. Conseguimos quantificar a entrada de africanos pelos impostos pagos - números que foram sistematizados por Menezes (2005) -, demonstrando alguns casos de apreensões de navios envolvidos com o comércio e a partir dos dados organizados pelo TSTD.

Tabela 1 - Número de entrada de africanos na Paraíba

\begin{tabular}{lll}
\hline Anos & Menezes & TSTD \\
\hline $\mathbf{1 6 9 4}$ & & 567 \\
$\mathbf{1 6 9 8}$ & & 244 \\
$\mathbf{1 7 1 4}$ & 170 & ---- \\
$\mathbf{1 7 1 5}$ & 270 & --- \\
$\mathbf{1 7 1 8}$ & ---- & 388 \\
$\mathbf{1 7 2 0}$ & --- & 491 \\
$\mathbf{1 7 2 3 - 2 4}$ & 140 & ---- \\
$\mathbf{1 7 2 4 - 2 5}$ & 50 & ---- \\
$\mathbf{1 7 2 5 - 2 6}$ & 249 & 289 \\
$\mathbf{1 7 2 6 - 2 7}$ & 797,6 ou & 439 \\
& 402 & \\
$\mathbf{1 7 2 7 - 2 8}$ & 161,7 ou & 388 \\
& 76 & \\
$\mathbf{1 7 2 8 - 2 9}$ & 114,8 & 776 \\
$\mathbf{1 7 3 1 - 3 2}$ & 94 & ---- \\
$\mathbf{1 7 3 2 - 3 3}$ & 252,4 ou & 196 \\
& 200 & \\
$\mathbf{1 7 3 3 - 3 4}$ & 114 & 520 \\
$\mathbf{1 7 3 5}$ & ---- & 196 \\
$\mathbf{1 7 3 6 - 3 7}$ & 214 & ---- \\
\hline $\mathbf{1 7 3 9 - 4 1}$ & 481 & ---- \\
$\mathbf{1 7 4 4 - 4 5}$ & 204,8 & 388 \\
\hline $\mathbf{1 7 4 5 - 4 6}$ & 182 & ---- \\
$\mathbf{1 7 4 7 - 4 8}$ & 688,5 & ---- \\
\hline $\mathbf{1 7 5 3 - 5 4}$ & 562,2 & ---- \\
\hline $\mathbf{1 7 8 4}$ & & 353 \\
$\mathbf{1 8 2 0}$ & & 50 \\
$\mathbf{1 8 2 3}$ & & 239 \\
\hline
\end{tabular}

${ }^{14}$ AHU_CU_014, Cx. 47, D. 3345, 1806.

Revista da ABPN • v. 12, n. Ed. Especial - Caderno Temático: "Africanos, escravizados, libertos biografias, imagens e experiências atlânticas" • agosto de 2020, p. $197-222$ 
Fonte: Quadro adaptado de Menezes (2005, p. 146; 2010, p. 48) https://www.slavevoyages.org/voyage/database\#tables. ${ }^{15}$

Em geral, os dados apresentados por Menezes e pelo TSTD apresentam complementaridade. Em apenas alguns anos, os números demonstram grande disparidade. Isso diz respeito às dificuldades de quantificar por meio da documentação. No caso de Menezes, dividiu-se o valor do que foi arrecado pelo que era pago "por cabeça". ${ }^{16}$ Já o TSTD, muitas vezes, estabelece estimativas por navio, não conseguindo apresentar os números exatos. Apesar disso, esses dados podem nos dar uma noção de como a capitania/província se relacionava com a África.

O que podemos constatar é que, apesar das limitações econômicas, a Paraíba apresentava uma regularidade na entrada de africanos, em especial, na primeira metade do século XVIII. Às frequentes dificuldades da produção açucareira eram apresentadas, como principal alternativa, pedidos para isenção de escravos, como já citamos anteriormente. Devemos pensar que muitos ficavam nos engenhos, outros iam para as Minas e outros para o interior. De forma que, apesar das dificuldades econômicas, a lógica da sociedade escravista conseguiu se reproduzir na Paraíba.

A partir da segunda metade do século XVIII, houve uma forte ruptura nessa entrada. Isso não significa dizer que os africanos não estavam sendo importados. A principal explicação para isso consiste no fato de que, desde 1759, as transações atlânticas de escravos ficaram sob o monopólio da Companhia Geral de Comércio Pernambuco e Paraíba. Isso representou uma forte mudança na maneira de comprar escravos na África, ficando os moradores desta capitania mais dependentes das relações com Pernambuco, fato que permaneceu sem muitas alterações no decorrer do XIX. Essa ruptura, inclusive, gerava muita insatisfação nos senhores de engenhos da Paraíba, pois parte dos africanos importados pela Companhia ou ficavam em Pernambuco ou desciam para o Rio de Janeiro. Em estudo sobre esse período, António Carreira (1980, p. 234) informava que - sem levar em consideração os possíveis contrabandos - durante o

${ }^{15}$ Esta tabela também foi utilizada em Guimarães (2018) e atualizada: Acesso em 26 jun. 2020. Confirmamos os dados referentes ao século XVIII e acrescentamos outros sobre o século XVII e XIX.

${ }^{16}$ No início do século XVIII, a Coroa portuguesa estabeleceu o imposto para a entrada de cada escravo que fosse comprado na Costa da Mina ou no Porto de Ajudá

Revista da ABPN • v. 12, n. Ed. Especial - Caderno Temático: "Africanos, escravizados, libertos biografias, imagens e experiências atlânticas" • agosto de 2020, p. $197-222$ 
funcionamento da Companhia cerca de 345 africanos foram vendidos para a Paraíba. Na tabela percebemos a entrada de 353 pessoas no ano de 1784 .

Como estamos defendendo, a entrada constante de africanos na Paraíba montou uma sociedade escravista estável na capitania/província. Isso pode ser percebido a partir dos dados demográficos que temos desde o final do século XVIII até o XIX.

Tabela 2 - Dados demográficos da Paraíba $(1762$ - 1871)

\begin{tabular}{|c|c|c|c|c|c|c|c|c|c|c|c|}
\hline & $\begin{array}{l}\text { Capitania/ } \\
\text { Província }\end{array}$ & Livres & $\%$ & Escravos & $\%$ & Capital & Livres & $\%$ & Escravos & $\%$ & Fontes \\
\hline 1762 & 39.158 & 29.865 & 79 & 9.293 & 21 & & & & & & $\overline{\mathrm{A}}$ \\
\hline 1782 & 52.468 & --- & & --- & & 17.522 & --- & & --- & & B \\
\hline 1798 & 28.804 & 19.907 & 69 & 8.897 & 31 & 6.015 & 4.138 & 70 & 1.815 & 30 & B \\
\hline 1799 & 50.464 & --- & & --- & & --- & --- & & --- & & B \\
\hline 1800 & 56.475 & --- & & --- & & --- & --- & & --- & & B \\
\hline 1801 & 55.573 & 44.635 & 81 & 10.569 & 19 & --- & & & & & B \\
\hline 1802 & 50.835 & 39.968 & 79 & 10.667 & 21 & 10.809 & 7.770 & 73 & 2.959 & 27 & B \\
\hline 1804 & 38.814 & --- & & --- & & 10.843 & 8.498 & 78 & 2.345 & 21 & B \\
\hline 1805 & 49.358 & --- & & --- & & 10.832 & 7.787 & 72 & 3.063 & 28 & B \\
\hline 1808 & 95.162 & --- & & --- & & --- & --- & & --- & & B \\
\hline 1811 & 122.407 & --- & & --- & & --- & --- & & --- & & B \\
\hline 1812 & 95.162 & --- & & --- & & --- & --- & & --- & & B \\
\hline 1819 & --- & --- & & 16.723 & & --- & --- & & --- & & B \\
\hline 1823 & 122.407 & $\begin{array}{l}102.40 \\
7\end{array}$ & 83 & 20.000 & 17 & --- & --- & & --- & & B \\
\hline 1828 & 122.407 & $\begin{array}{l}102.40 \\
7\end{array}$ & 83 & 20.000 & 17 & 6.000 & --- & & --- & & B \\
\hline 1838 & 55.124 & --- & & --- & & --- & --- & & --- & & B \\
\hline 1839 & 55.124 & --- & & --- & & 9.060 & --- & & --- & & B \\
\hline 1841 & --- & --- & & --- & & 21.865 & --- & & --- & & B \\
\hline 1842 & 227.870 & --- & & --- & & --- & --- & & --- & & B \\
\hline 1843 & 227.870 & --- & & --- & & --- & --- & & --- & & B \\
\hline 1850 & 206.952 & $\begin{array}{l}178.47 \\
9\end{array}$ & 86 & 28.473 & 14 & 21.295 & $\begin{array}{l}18.18 \\
3\end{array}$ & 83 & 3.512 & 17 & B \\
\hline 1871 & 219.104 & $\begin{array}{l}200.77 \\
7 \\
\end{array}$ & 92 & 18.327 & 11 & & & & & & $\mathrm{C}$ \\
\hline
\end{tabular}

Fontes: A- Ribeiro Júnior (2004, p.72); B- Quadro sistematizado por Guimarães (2018); C Medeiros; Sá (1999, p. 55).

Revista da ABPN • v. 12, n. Ed. Especial - Caderno Temático: "Africanos, escravizados, libertos biografias, imagens e experiências atlânticas” • agosto de 2020, p. $197-222$ 
A tabela 2 nos permite identificar que a população escrava na Paraíba variou, por décadas, entre $30 \%$ e $17 \%$. A partir de meados do século XIX, essa proporção caiu, devido às mudanças econômicas e sociais vivenciadas em todo o Brasil, que culminaram na crise do sistema escravista, afetando de forma mais intensa as províncias do Norte. Apesar dessas mudanças, não deixou de haver uma quantidade significativa de pessoas escravizadas circulando pelas ruas das vilas e cidades da província.

Vale ressaltar que a crise do sistema escravista, vivenciada na segunda metade do século XIX, não significou a redução da quantidade de pessoas negras que, aos poucos, se tornavam libertas e livres. O que percebemos, a partir de outros dados, é que o número dessas pessoas era alto. Para se ter uma ideia, a proporção de pessoas pretas (ou seja, nascidas na África) variou por vários anos entre 10 e $25 \%$. Se somarmos a esses números a quantidade de pardos e mulatos, podemos dizer, com tranquilidade, que a Paraíba era formada em sua maioria por pessoas não brancas.

Quadro 1 - Proporção de pretos na população da Paraíba (1798 - 1812)

\begin{tabular}{|c|c|c|c|}
\hline Ano & População de pretos & Total da Capitania & Proporção \\
\hline 1798 & 10.015 & 39.894 & $25,10 \%$ \\
\hline 1799 & 12.319 & 50.464 & $24,41 \%$ \\
\hline 1800 & 12.840 & 56.475 & $22,73 \%$ \\
\hline 1801 & 12.753 & 55.573 & $22,94 \%$ \\
\hline 1802 & 13.469 & 50.835 & $26,49 \%$ \\
\hline 1804 & 10.036 & 38.814 & $25,85 \%$ \\
\hline 1805 & 11.822 & 49.358 & $23,95 \%$ \\
\hline 1811 & 12.396 & 122.407 & $10,12 \%$ \\
\hline 1812 & 18.004 & 95.162 & $18,91 \%$ \\
\hline
\end{tabular}

Fontes: Oliveira (2007, p. 162); Pinto (1977, Vol. I, p. 241-242). ${ }^{17}$

Os números referentes aos anos de 1811 e 1812 foram apresentados por Irineu Pinto (1977, p. 241-242). Apesar de não informar de onde retirou esta informação, eles se transformaram em importantes referências para se pensar a demografia da Paraíba. Se o percentual de pessoas pretas variou entre 10 e $18 \%$, as pessoas classificadas como

${ }^{17}$ Dados deste quadro também estão presentes em Guimarães (2018).

Revista da ABPN • v. 12, n. Ed. Especial - Caderno Temático: "Africanos, escravizados, libertos biografias, imagens e experiências atlânticas” • agosto de 2020, p. $197-222$ 
mulatas eram cerca de 50 e $39 \%$, respectivamente. Ou seja, somando pretos e mulatos, a capitania era composta por cerca de $60 \%$ de negros/as. ${ }^{18}$ Se analisarmos a quantidade de pessoas nascidas na capital consideradas pardas no decorrer do século XIX, temos cerca de $36 \%$, o que aponta a possibilidade de reprodução natural dessa população escravizada, ocorrendo em paralelo com a importação de africanos, que neste período havia diminuído (ROCHA, 2009, p. 138).

Vale lembrar que, na virada dos séculos XVIII para XIX, o algodão despontava como uma importante atividade produtiva que permitiu um crescimento econômico da capitania. Somado a isso, em 1799, a Paraíba ganhou sua autonomia, ainda que permanecesse com fortes relações comerciais com Pernambuco. De forma que as condições econômicas eram mais favoráveis e isso permitiu um aumento da população negra na capitania.

Esses números são importantes para pensarmos o quadro geral dessa sociedade escravista. Eles representam, sobretudo, pessoas. Além do levantamento de dados quantitativos, é fundamental - e essa tem sido uma tendência da historiografia mais recente - refletir sobre as experiências de vida dessas pessoas, de seu agir político, de forma individual e coletiva. Afinal, como era a vida dessas pessoas escravizadas na Paraíba? Dessa feita, passamos a narrar algumas histórias de resistências - individuais e coletivas - de africano(a)s, crioulo(a)s, pardo(a)s, mestiço(a)s, variado(a)s povos indígenas; mulheres, homens e crianças que de alguma forma foram subjugado(a)s pela sociedade escravista nesse lado do Atlântico Negro.

\section{FAMÍLIA CATIVA NA ZONA RURAL: BALDOÍNA E A LIBERDADE DE SEUS/SUAS FILHOS/AS}

Pesquisas inaugurais, como a do historiador Slenes (1988, 1999), contribuíram para a formação de um campo de estudo que hoje dispõe de uma vasta produção, apoiada em extensa pesquisa documental, na qual os/as historiadores/as passaram a reavaliar o parentesco de mulheres, crianças e homens escravizados, mostrando que, apesar dos limites sociais e da violência imposta pelo sistema escravista, eles

${ }^{18}$ Este debate encontra-se em Rocha (2009, p. 110-11).

Revista da ABPN • v. 12, n. Ed. Especial - Caderno Temático: "Africanos, escravizados, libertos biografias, imagens e experiências atlânticas" • agosto de 2020, p. $197-222$ 
construíram uma lógica de sobrevivência e resistência e se reinventaram culturalmente, ampliando suas relações sociais e estabelecendo novas formas de vínculos de parentesco no contexto da diáspora africana nas Américas (SLENES, 1999; REIS, 2001; ROCHA, 2009).

Nesse sentido, destacamos a história de uma mulher cativa residente na zona rural da Paraíba, que conseguiu comprar a carta de liberdade de dois filhos durante o processo da partilha de herança de um proeminente escravizador e dono de três engenhos de cana de açúcar. Trata-se de Baldoína, mãe escravizada de nove crianças. Ela vivia numa área de engenhos de açúcar - em 1851, eram 159 -, mas também de produção de algodão para atender o mercado do capitalismo industrial, lavoura de subsistência e criação de animais, com destaque para o gado. A população escravizada na área litorânea era de cerca de 9.733 indivíduos, num total de 28.566 cativos, sendo, portanto, quase 35\% desse grupo social no território paraibano (GALLIZA, 1979, p. 40)

Baldoína pertencia ao escravizador Joaquim Gomes da Silveira, suas filhas e seus filhos nasceram entre os anos de 1850 e 1873, a saber: Paula (nascida por volta da década de 1850), Bernarda (1858), Josefa (1861), Marcos (nascido por volta de 1863), Pio (nascido por volta de 1864), Celestina (1868), Luzia (1870), Lúcio (1871) e Atanázio (1873). ${ }^{19}$

Após a morte de Joaquim Gomes da Silveira, como era de costume, iniciou-se o processo de elaboração do inventário. Feito o levantamento de sua herança, na ocasião da divisão de sua riqueza (1870), Baldoína conseguiu comprar a carta de alforria de dois de seus filhos, Marcos e Pio e sua filha mais velha, Paula, foi alforriada no testamento do senhor (1866). Talvez tenha sido uma forma de reconhecer uma vida de trabalho e de sacrifícios de Baldoína, ou mesmo o aumento de sua riqueza com a posse de tantas crianças paridas no ventre cativo (TESTAMENTO de Joaquim Gomes da Silveira (Arquivo do Tribunal da Justiça da Paraíba/ATJPB, 1866).

\footnotetext{
${ }^{19}$ Conforme consta no Livro de Batismo de Livramento, 1863-74, fls. 109 e 163, no Arquivo Eclesiástico da Arquidiocese da Paraíba/AEAPB. A idade das crianças encontrava-se no Inventário. Esta personagem histórica foi revelada em estudo anterior de Rocha, sendo que neste artigo, apresentamos nova abordagem, posto que Baldoína é retratada como uma das mulheres que experienciou uma forma de resistência pouco comum na Paraíba e em outras partes do Brasil.
}

Revista da ABPN • v. 12, n. Ed. Especial - Caderno Temático: "Africanos, escravizados, libertos biografias, imagens e experiências atlânticas” • agosto de 2020, p. $197-222$ 
Baldoína fazia parte de um grupo de famílias monoparentais, ou seja, mães solteiras com suas crianças. A análise do documento de Gomes da Silveira nos mostra a mesquinhez dos herdeiros, pois as cartas de alforria de Pio e Marcos foram adquiridas por valores muito acima do "preço" de ambos. No inventário, o menino Pio foi classificado por $200 \$ 000$ réis, mas sua alforria foi obtida após o pagamento de 330\$000; já Marcos constava por $300 \$ 000$ réis, mas se exigiu a quantia de 400\$000 réis pela sua liberdade. Apesar de valores significativos para uma mulher escravizada, Baldoína conseguiu depositar os $730 \$ 000$ réis exigidos e comprar as alforrias. ${ }^{20}$ Considerando a comercialização das duas crianças, os Gomes da Silveira tiveram um lucro de $230 \$ 000$ réis.

A respeito dos outros membros da família da escravizada Baldoína, ficamos sabendo que duas de suas filhas (Celestina e Luzia) foram herdadas por Ana Gomes da Silveira, enquanto seus outros filhos foram divididos entre mais dois filhos de Joaquim Gomes da Silveira. Se fossem herdados pelos Gomes da Silveira, Pio e Marcos teriam como proprietário Taciano Gomes da Silveira. A irmã deles, a menina Josefa, foi herdada por Ismênia Gomes da Silveira. Esta partilha nos revela também a divisão da família cativa e, certamente, as dores da separação e os limites impostos pelo sistema escravista e o desalento de serem escravizadas, portanto, não eram donas nem de si e nem de seus filhos/as. Felizmente, como destacamos anteriormente, a mãe-escravizada conseguiu livrar três filhos da escravidão (Pio, Marcos e Paula). Mesmo assim, judicialmente, ela foi separada de três filhas.

Um aspecto que merece ser comentado acerca da trajetória de vida de Baldoína refere-se ao fato de ela ter gerado muitos filhos durante seu período reprodutivo, ocorrido no período pós-1850, que marca a crise do escravismo e a intensificação do tráfico interprovincial, o que gerou o encarecimento da mão de obra cativa. Ela não é um caso isolado. Na Paraíba oitocentista, a reprodução endógena parece ter funcionado como mecanismo da classe senhorial para manutenção do escravismo e enfrentar a "falta de braços" de escravizados no contexto oitocentista (ROCHA, 2009). Outra maneira de obtenção de mão de obra para as atividades agrícolas e urbanas, foi o

${ }^{20}$ Conforme Inventário de Joaquim Gomes da Silveira, 1870, ATJPB.

Revista da ABPN • v. 12, n. Ed. Especial - Caderno Temático: "Africanos, escravizados, libertos biografias, imagens e experiências atlânticas" • agosto de 2020, p. $197-222$ 
emprego de pessoas negras livres e libertas e brancas pobres a partir de contratos de trabalhos variados, como moradoras, agregadas, assalariadas e meeiras (MEDEIROS, 1999), uma vez que, segundo dados do primeiro censo brasileiro (1872), a maior parte da população paraibana era formada por pessoas de condição livre ou liberta -354.700 $(94,2 \%)$ de um total de 376.226 habitantes. Ainda há que ressaltar que os indivíduos negros formavam a maior parte dos domiciliados em tal território, pois eram $50 \%$ de pardos e $9 \%$ de pretos, correspondiam, portanto, a 59\% do total da população da Paraíba Imperial.

Décadas antes dessa contagem populacional, Baldoína, que estava em fase produtiva e reprodutiva, tornou-se mãe de potenciais trabalhadores e trabalhadoras com a mesma condição, pois no Brasil prevaleceu o partus sequitur ventrem (o/a filho/a segue a condição jurídica da mãe). Somente, em 1871, com a Lei Rio Branco, o ventre se tornou "livre". Podemos compreender, assim, a dupla importância (e violência do sistema) das mulheres escravizadas na constituição de famílias na Zona da Mata da Paraíba, como trabalhadora e reprodutora de mão de obra cativa, que poderia minimizar a crise para seus proprietários e em alguns casos aumentar a sua riqueza. Por outro lado, para algumas mulheres, a maternidade era uma forma de estabelecer laços afetivos, de lutar pela liberdade de seus filhos e suas filhas, como foi o caso de Baldoína que teve êxito na estratégia criada para livrar gerações futuras do cativeiro.

Consideramos relevante também o caso de Baldoína, uma mulher cativa da zona rural dispor de pecúlio para compra de cartas de alforria. Isso nos leva a questões ainda sem respostas. Será que tal prática era comum? A escravizada em destaque detinha algum roçado de produção de alimentos e os vendia na região para seus vizinhos? Ou ela desempenhava alguma atividade remunerada nas casas de engenho da vizinhança? Enfim, Baldoína não é um caso emblemático. Pelo contrário, ela nos mostra que ainda há temas e sujeitos sociais que merecem ser pesquisados para, desse modo, revelar as ações de resistência cotidiana, mas também histórias de tensões, de contradições, de derrotas e de algumas vitórias numa sociedade em que pessoas eram possuídas por outras e, sem dúvida, assinalando para a complexidade das vivências de sujeitos escravizados e livres no Brasil.

Revista da ABPN • v. 12, n. Ed. Especial - Caderno Temático: "Africanos, escravizados, libertos biografias, imagens e experiências atlânticas” • agosto de 2020, p. $197-222$ 
Outras formas de resistências foram protagonizadas pelos sujeitos africanos e seus descendentes na Paraíba. Podemos mencionar, entre outras, tanto as revoltas coletivas, como a ação dos cativos de Campina Grande durante o movimento político do Quebra-Quilos (1874) quanto as ações individuais, como participação em irmandades negras, em todo o território da Paraíba, e em festas negras, nas quais são demonstradas as agências e o protagonismo de indivíduos que viveram sob a égide do escravismo, uma forma de exploração que teve forte vinculação e fortalecimento do capitalismo nos diferentes contextos históricos da escravidão atlântica (LIMA, 2006; LIMA, 2013). Uma outra importante forma de tentar sair da lógica escravista estava na formação de quilombos, também presentes na história da Paraíba.

\section{"VIVER NAS MATAS", MAS NÃO ISOLADOS: COMUNIDADES QUILOMBOLAS NA PARAÍBA ESCRAVISTA}

Apesar das dificuldades em estudar os quilombos do período escravista na Paraíba, uma vez que a documentação é esparsa e lacunar, vale visibilizar a existência de alguns agrupamentos de fugitivos (as): o "Mocambo do Cumbe" (século XVIII), o Quilombo do Engenho do Espírito Santo (segunda metade do século XIX) e o do Livramento (final do século XIX). Os dois primeiros estiveram localizados na Zona da Mata e o último no Sertão paraibano.

Um dos mais antigos mocambos da Paraíba, o Quilombo do Cumbe, apresenta controvérsias sobre sua localização, se ele se constituiu na Zona da Mata ou no Agreste paraibano. ${ }^{21}$ Análises atuais de Lima (2012) indicam que o mencionado reduto de fugidos estava situado, geograficamente, nas proximidades do litoral, em áreas não ocupadas por europeus e nem por atividade comercial, como a lavoura canavieira, designadas como "sertões". Vale frisar que o termo "sertão" era uma forma do colonizador nomear um território que não havia sido reocupado e repovoado na então

21 "No Brasil foram denominadas inicialmente somente como mocambos, depois a nomenclatura Quilombos foi generalizada. Estes dois termos em muitas partes da África Central significavam acampamentos e no século XVII a palavra quilombo também era associada aos guerreiros imbangalas (jagas) e seus rituais de iniciação. Já mukambu, tanto em Kimbundu, como em Kicongo -línguas africanas -, significava pau de fieira, tipo de suportes com forquilhas utilizados para erguer choupanas nos acampamentos" (THEODORO; MORAES; GOMES, 2015, p. 215).

Revista da ABPN • v. 12, n. Ed. Especial - Caderno Temático: "Africanos, escravizados, libertos biografias, imagens e experiências atlânticas" • agosto de 2020, p. $197-222$ 
capitania da Paraíba, num processo iniciado em 1574 que, após inúmeros conflitos contra os povos indígenas, resultou na ampliação das terras dominadas pela coroa portuguesa/coroa ibérica, em 1585, originando o atual Paraíba.

O Mocambo do Cumbe tem sido indicado por ser um território que recebeu os quilombolas de Palmares (c.1580), após sua destruição (1695), em Pinto (1977, p. 95) e Lima (2016). Poucos anos depois desse episódio, em 1701 as autoridades coloniais, nas pessoas de capitão Jerônimo Tovar de Macedo e João Tavares da Costa, em defesa de um projeto colonial que passava pela escravização de pessoas, tentaram arrasar o Quilombo Cumbe com a formação de uma expedição composta de quarenta homens, que resultou no aprisionamento de "vinte e cinco negros".

Décadas depois, em 1731, o Mocambo do Cumbe foi novamente encontrado nas fontes históricas informando que, desde 1717, o quilombo estava vivo e identificaram "índios" e "negros fugidos" em número de "setenta". A voz oficial dizia que estes vinham realizando roubos de moradores da vizinhança (Carta Régia, de outubro de 1731). ${ }^{22}$ Apelavam ainda para que se "fizesse entrada no mocambo e aprisionassem quanta gente nele se houver". Após a repressão das forças coloniais, cinco indígenas foram mortos e apreenderam "mais de cinquenta negros" e outros três conseguiram fugir pelas "veredas impenetráveis" em direção à capitania de Pernambuco.

Vale destacar também que esta era uma região que possuía uma presença indígena forte, em aldeias. No documento sobre o quilombo do Cumbe, em 1731, faz-se referência a índios fugidos da Aldeia Cariri. Nas proximidades de Paratibe e Gajaú, havia as aldeias de Taquara, Alhandra e Jacoca. A possibilidade de alianças entre os povos negros e indígenas na Paraíba assustava, constantemente, as autoridades régias.

Em 1735, o capitão-mor Pedro Monteiro de Macedo informava que, ao norte, na Baía da Traição, onde havia uma aldeia indígena, eram estes "atrevidos e orgulhosos" e que haviam tentado "uma sublevação geral convidando não só para ela a Aldeia daquela capitania, mas ainda as mais distantes da de Pernambuco" (AHU_CU_014, Cx. 9, D. 769, 08/02/1735). Esse potencial ficaria ainda mais explosivo se houvesse uma aliança com os negros e pardos. Isso foi lembrado diversas vezes por Jeronimo José de Mello e Castro ao final do século XVIII. Dizia ele, na década de 1780, ser "evidente perigo a

${ }^{22}$ A Carta Régia (1731) encontra-se no texto de Vidal 1988 [1934], p. 109-110.

Revista da ABPN • v. 12, n. Ed. Especial - Caderno Temático: "Africanos, escravizados, libertos biografias, imagens e experiências atlânticas” • agosto de 2020, p. $197-222$ 
que se expõem esta cidade de maior parte de pretos, e pardos, cercada de cinco vilas de índias uma em distância de quatro léguas, outra de sete, e as mais de doze" (AHU_CU_014, Cx. 27, D. 2067, 26/04/1780). Reconhecia ainda a incapacidade de conter uma revolta com essas proporções. Alguns anos depois, reforçava que "ficou esta praça sem providência $\mathrm{p}$ [ara] algum levante popular que é a maior parte de pardos, e pretos aliançados com os índios, fáceis em se levantarem como aconteceu na Vila de Mamanguape [Monte-mor] que com trabalho subjuguei” (AHU_CU_014, Cx. 28, D. $2133,14 / 08 / 1784)$.

No final do século XVIII, outros quilombos se formaram na região da Mata Sul da Paraíba, próximos à fronteira com Pernambuco. Carmelo Nascimento Filho (2006) informa ter encontrado em fontes históricas a existência de dois quilombos: Paratibe e Guajú. Ao que tudo indica, esses quilombos estavam articulados ou tinham contato com o que ficou conhecido como quilombo do Malunguinho (ou Catucá), no início do século XIX. ${ }^{23}$ Atualmente, a comunidade do Paratibe ainda existe, ao sul da cidade de João Pessoa, sendo um quilombo urbano. As terras ao redor deste quilombo começaram a ser um espaço que agregou pessoas livres pobres e "foram legalizadas por ocasião da Lei de Terras (1850) por muitos posseiros, a maioria analfabeta" (GONÇALVES, 2013, p. 179), o que nos demonstra as mais variadas formas de reorganização da resistência e sobrevivência das pessoas negras na região, incluindo a formação de redutos e estabelecendo relações sociais com a população da Paraíba, e, mesmo, de Pernambuco. ${ }^{24}$

Em 1851, autoridades provinciais tiveram uma ação de repressão, que resultou na destruição do Quilombo do Engenho do Espírito Santo, em cujas fontes oficiais havia relatos de acusação de escravizados realizando "furtos, roubos, incêndios em casas [de engenhos de açúcar]" e também agredindo membros da classe senhorial da região da Zona da Mata. Como resultante da ação violenta da força policial, três cativos

\footnotetext{
${ }^{23}$ De acordo com Marcus Carvalho $(1991$, p. 6) a floresta do Catucá estava na região que compreendia os “ mangues e rios da região [ao norte do Recife], chegando não muito longe da costa em Paratibe e daí a Pasmado, perto da ilha de Itamaracá, até o povoado de Tejucupapo, próximo à vila de Goiana, já quase na fronteira com a província da Paraíba". Esse quilombo foi mais documentado a partir do período da Independência.

${ }^{24}$ Importante pensar as relações entre esse passado de resistência de quilombos e a permanência na luta pelo direito à terra, consultar Theodoro; Moraes; Gomes (2015) e Domingues e Gomes (2013).
}

Revista da ABPN • v. 12, n. Ed. Especial - Caderno Temático: "Africanos, escravizados, libertos biografias, imagens e experiências atlânticas” • agosto de 2020, p. $197-222$ 
forma presos, um foi morto (Bento) e outros dois conseguiram fugir. Bento portava um "clavinote com munição", entretanto, foi lançado por terra após ter recebido "um tiro no peito" (GALLIZA, 1979, p. 96). Como podemos observar, quilombos em terras paraibanas amedrontavam as autoridades também no século XIX. As evasões de mulheres, crianças e homens continuaram por todas as regiões não só da Paraíba, mas também pelas capitanias/províncias da vizinhança e, em alguns casos, para áreas mais distantes (DIAS, 2013).

Um último quilombo da fase escravista, até então identificado por estudos recentes, é o de Livramento. Esse mocambo foi formado no final do século XIX, no Semiárido da Paraíba, no atual município de José de Princesa e próximo das cidades de Princesa Isabel e de Triunfo/PE. As escassas fontes históricas indicam que sua formação ocorreu com pessoas negras fugidas do cativeiro de Alagoas. Elas se estabeleceram no “Alto da Serra Grande do Pajeú", local estratégico para dificultar o acesso do Estado repressor. Estes primeiros moradores formaram "locas, cavernas" para se abrigarem e garantir a sobrevivência em tal comunidade. Os povos indígenas também participaram desse e de outros quilombos (MENESES, 2010, p. 75).

Nas áreas da Zona da Mata, após a repressão aos(às) quilombolas, a cada década se consolidou como uma importante área da agroexportação de açúcar, de engenhos, que, no final do século XIX, passaram por mudanças com a formação dos engenhos centrais e, por fim, em usinas, que permanecem ativas até a atualidade, como já informamos anteriormente.

Importa salientar ainda que, nos dias atuais, a Paraíba dispõe de cerca de quarenta comunidades remanescentes de quilombolas reconhecidas pelos órgãos federais, localizadas em todas as regiões do estado, de forma que a seguinte afirmação de Galliza (1979, p. 97): [...] "só esporadicamente, o negro foi elemento perturbador da economia sertaneja", precisa ser problematizada, visto que cerca de trinta comunidades quilombolas estão localizadas no Sertão paraibano. Mais estudos históricos em fontes primárias poderiam nos oferecer respostas sobre inúmeras questões, como as que seguem: Será que as mulheres e os homens quilombolas tiveram pleno êxito em se manterem invisíveis por séculos no cenário paraibano? De fato, estiveram vivendo em áreas isoladas e desconhecidas das autoridades e não deixaram vestígios? De imediato,

Revista da ABPN • v. 12, n. Ed. Especial - Caderno Temático: "Africanos, escravizados, libertos biografias, imagens e experiências atlânticas" • agosto de 2020, p. $197-222$ 
não podemos deixar de ressaltar a exiguidade de estudos sobre os quilombos na Paraíba escravista. Urge que estudiosos/as da história enfrentem o desafio de investigar o referido tema para ampliação de nossos conhecimentos acerca das comunidades formadas por mulheres e homens do passado que tiveram a coragem de se erguer contra a opressão escravista.

\section{CONSIDERAÇÕES FINAIS}

A Paraíba construiu uma longa experiência escravista, que se reflete ainda nas relações sociais atuais. Para atender a interesses econômicos e sociais de uma elite, milhares de homens e mulheres africanas foram aprisionadas, tornadas escravas, desembarcaram na referida capitania/província e reorganizaram suas vidas a partir de diversas relações sociais construídas, buscando sempre construir formas de liberdades diante de uma sociedade baseada na opressão. A partir do século XVIII, e durante o século XIX, conseguimos ter mais informações sobre o tráfico dessas pessoas e suas experiências de vida e de seus descendentes. Com essas fontes, apresentamos um quadro geral de como estava a economia e demografia da Paraíba, identificando a importância do comércio atlântico de pessoas e da reprodução natural como importantes formas de manutenção dessa sociedade escravista.

Os fragmentos das experiências de vida de algumas pessoas escravizadas permitem-nos recuperar alguma historicidade sobre elas, revelando-nos que apesar de estarem limitadas por circunstâncias históricas, muitas mulheres e homens agiram de forma a afirmar a sua humanidade, a contrapor-se às regras do sistema escravocrata, mesmo correndo o risco de serem punidas pela classe senhorial. Ademais, considerando as histórias de pessoas escravizadas o protagonismo de escravizados/as, o que nos indicam uma resistência persistente, que passaram pelo rompimento com o escravismo e pela negociação no interior do sistema para minimizar o sofrimento humano, mas também na construção de estratégias para conquista de liberdade e da deslegitimação da opressão escravista, com o agir político individuais no âmbito do interior escravista (família escrava) e de forma mais direta com a formação de comunidades quilombolas.

Revista da ABPN • v. 12, n. Ed. Especial - Caderno Temático: "Africanos, escravizados, libertos biografias, imagens e experiências atlânticas" • agosto de 2020, p. $197-222$ 
Muito ainda precisamos avançar na compreensão do passado escravista, afinal, por décadas, a historiografia não se voltou para o estudo da escravidão na Paraíba. Todavia, novas pesquisas têm sido produzidas, dando destaque às formas como essa sociedade se organizou e como, na medida do possível, essas pessoas negras (livres, libertas e escravizadas) se posicionaram e viveram em contexto adverso.

\section{REFERÊNCIAS BIBLIOGRÁFICAS}

\section{Fontes Históricas}

Digitais

TRANSATLANTIC SLAVE TRADE DATABASE. Disponível em: https://www.slavevoyages.org. Acesso em 26 jun. 2020.

Impressas

PINTO, Irineu. Datas e Notas para a História da Paraíba. João Pessoa: Universitária/UFPB, 1977, vol. 1.

$\underline{\text { Manuscritas }}$

Arquivo Histórico Ultramarino (AHU)

AHU_CU_014, Cx. 1, D. 95, 7/10/1675

AHU_CU_014, Cx. 3, D. 226, 03/09/1699

AHU_CU_014, Cx. 5, D. 360, 08/06/1717

AHU_CU_014, Cx. 5, D. 392, 12/10/1722

AHU_CU_014, Cx. 9, D. 769, 08/02/1735

AHU_CU_014, Cx. 27, D. 2067, 26/04/1780

AHU_CU_014, Cx. 28, D. 2133, 14/08/1784

Arquivo Eclesiástico da Arquidiocese da Paraíba/AEAPB

Livros de Batismos - 1833-1841

Livros de Batismos - 1846-1850

Livros de Batismos - 1863-74

Arquivo do Tribunal da Justiça da Paraíba/ATJPB

Testamento de Joaquim Gomes da Silveira, 1866

Arquivo do Instituto Histórico e Geográfico Paraibano/AIHGPB

Livro de Notas da Cidade da Parahyba (1841-1846)

$\underline{\text { Bibliografia }}$

BANAL, Alberto; FORTES, Maria Ester P. (Orgs). Quilombos na Paraíba: a realidade de hoje e os desafios para o futuro. João Pessoa: Imprell Gráfica e Editora, 2013.

Revista da ABPN • v. 12, n. Ed. Especial - Caderno Temático: "Africanos, escravizados, libertos biografias, imagens e experiências atlânticas” • agosto de 2020, p. $197-222$ 
CALAINHO, Daniela B. Jambacousses e gangazambas: feiticeiros negros em Portugal. AfroÁsia, n. 25, p. 141-176, 2001.

CARREIRA, Antônio. As Companhias Pombalinas: de Grão-Pará e Maranhão e Pernambuco e Paraíba. Lisboa: Editorial Presença, 1980.

CARVALHO, Marcus. O Quilombo do Catucá em Pernambuco. Cadernos CRH, Salvador/BA, v. 15, jul./dez., p. 05-25, 1991.

DIAS, Elainne Cristina J. Retrato falado: o perfil dos escravos nos anúncios de jornais da Paraíba (1850-1888). 2013. 167 f. Dissertação (Mestrado em História), Universidade Federal da Paraíba, João Pessoa, 2013. Disponível em: https://repositorio.ufpb.br/jspui/handle/tede/5992

DOMINGUES, Petrônio; GOMES, Flávio dos S. Histórias dos quilombos e memórias dos quilombos no Brasil: revisitando um diálogo ausente na Lei 10.639/03. Revista da Associação Brasileira de Pesquisadores/as Negros/as (ABPN), [S.1.], v. 5, n. 11, p. 05-28, out. 2013. Disponível em: tp://abpnrevista.org.br/revista/index.php/revistaabpn1/article/view/187 Acesso em: 12 jul. 2020.

FARIAS, Juliana B.; GOMES, Flávio dos S.; SOARES, Carlos Eugênio L.; MOREIRA, Carlos Eduardo de A. Cidades negras: africanos, crioulos e espaços urbanos no Brasil escravista do século XIX. São Paulo: Alameda, 2006.

FERNANDES, Irene Rodrigues da Silva. Comércio e subordinação: a Associação Comercial da Paraíba no processo histórico regional (1889-1930). João Pessoa: Universitária/UFPB, 1999

GALlIZA, Diana Soares. O declínio da Escravidão na Paraíba (1850-1888). João Pessoa: Editora Universitária/UFPB, 1979.

GONÇALVES, Maria Ronizia P. Comunidade Negra de Paratibe: de quilombo a bairro e de bairro a quilombo: 200 anos de posse de terra. In.: BANAL, Alberto; FORTES, Maria Ester P. (Orgs). Quilombos na Paraíba: a realidade de hoje e os desafios para o futuro. João Pessoa: Imprell Gráfica e Editora, 2013, p. 174-200.

GONÇALVES, Regina C. Guerras e Açúcares. Política e Economia na capitania da Paraíba (1585-1630). Bauru: EDUSC, 2007.

GUIMARÃES, Matheus S. Diáspora africana na Paraíba do Norte: trabalho, tráfico e sociabilidade na primeira metade do século XIX. João Pessoa: Editora do CCTA, 2018.

LOPES, Gustavo Acioli. Negócios da Costa da Mina e comércio atlântico: tabaco, açúcar, ouro e tráfico de escravos: Pernambuco (1654 - 1760). Tese (Doutorado em História), Universidade de São Paulo. 2008.

LIMA, Luciano M. Derramando susto: os escravos e o Quebra-Quilos em Campina Grande. Campina Grande: Ed. UFCG, 2006.

LIMA, Maria da Vitória B. Práticas religiosas de curandeiros e feiticeiros negros na Paraíba do Norte Oitocentista. In: COSTA, Valéria; GOMES, Flávio dos S. (Orgs.). Religiões Negras no Brasil: da escravidão à Pós-emancipação. São Paulo: Selo Negro, 2016, p. 266-279.

Revista da ABPN • v. 12, n. Ed. Especial - Caderno Temático: "Africanos, escravizados, libertos biografias, imagens e experiências atlânticas" • agosto de 2020, p. $197-222$ 
LIMA, Maria da Vitória B. Liberdade interditada, liberdade reavida: escravos e libertos na Paraíba escravista (século XIX). Brasília: FCP, 2013.

LIMA, Maria da Vitória B. Quilombos na Paraíba Colonial e Imperial. In: TELLA, Marco Aurélio Paz (Org.). Direitos Humanos, População Afro-Brasileira e Mulheres Negras. João Pessoa: Neabi/UFPB, 2012, p. 39-44.

LIMA, Solimar O.; SILVA, Rodrigo C. Do Norte ao Sul: escravidão Brasil século XVI-séc. XIX. Teresina: EDUFPI, 2018.

LOPES, Gustavo A. O tráfico transatlântico de escravos para o Brasil - séculos XVI-XIX. In: REIS, Isabel Cristina F.; ROCHA, Solange P. Diáspora Africana nas Américas. Cruz das Almas: Editora UFRB; Belo Horizonte: Fino Traço, 2016, p. 13-36.

LOPES, Nei. Novo dicionário Banto do Brasil. Rio de Janeiro: Pallas, 2006, p. 107.

MEDEIROS, Maria do Céu; SÁ, Ariane Norma de Menezes. O trabalho na Paraíba: das origens à transição para o trabalho livre. João Pessoa: Universitária/UFPB, 1999.

MENESES, Janine P. C de. Livramento, um quilombo desde o "tempo de pa trás". Dissertação (Mestrado em História), Universidade Federal de Pernambuco, 2010.

MENEZES, Mozart Vergetti. Colonialismo em ação: Fiscalismo, economia e sociedade na capitania da Paraíba, 1647 -1755. Tese (Doutorado em História), Universidade de São Paulo. 2005.

MOURA, Clóvis. Rebeliões da Senzala: quilombos, insurreições e guerrilhas. Rio de Janeiro: Conquista, 1972.

NASCIMENTO FILHO, Carmelo. Fronteira Móvel: os homens livres pobres e a produção do espaço da Mata Sul da Paraíba (1799-1801). Dissertação (Mestrado em Geografia), Universidade Federal da Paraíba, 2006.

OLIVEIRA, Elza Régias de. A Paraíba na crise do século XVIII: subordinação e autonomia (1755-1799). 2 ed. João Pessoa: Editora Universitária/UFPB, 2007.

REIS, Isabel Cristina F. História de vida familiar e afetiva de escravos na Bahia do século XIX. Salvador: EDUFBA, 2001.

REIS, João J.; GOMES, Flávio dos S. Liberdade por um fio: histórias dos quilombos no Brasil. São Paulo: Companhia das Letras, 1996.

RIBEIRO JÚNIOR, José. Colonização e Monopólio no Nordeste brasileiro: a Companhia Geral de Pernambuco e Paraíba, 1759-1780. 2 ed. São Paulo: Hucitec, 2004.

RIOS, Ana Lugão; MATTOS, Hebe Maria. Memórias do cativeiro: família, trabalho e cidadania no pós-abolição. Rio de Janeiro: Civilização Brasileira, 2005.

Revista da ABPN • v. 12, n. Ed. Especial - Caderno Temático: "Africanos, escravizados, libertos biografias, imagens e experiências atlânticas" • agosto de 2020, p. $197-222$ 
ROCHA, Solange P.; GUIMARÃES, Matheus S. O mundo trabalho na sociedade escravocrata brasileira: um panorama sobre a Paraíba escravista. In: OLIVEIRA, Tiago Bernardon de (Org.). Trabalho e trabalhadores no Nordeste: análises e perspectivas históricas em Alagoas, Pernambuco e Paraíba. Campina Grande: EdUEPB, 2015, p. 2356.

ROCHA, Solange P. Gente negra na Paraíba oitocentista: população, família e parentesco espiritual. São Paulo: Unesp, 2009.

RUSSEL-WOOD, Anthony John. Centro e Periferia no mundo luso-brasileiro, 1500-1808. Revista Brasileira de História. São Paulo, Humanitas, v.18, n. 36, p. 187-249, 1998.

SANTANA, Martha Falcão de Carvalho e Morais. Nordeste, açúcar e poder: um estudo da oligarquia açucareira na Paraíba (1920-1962). João Pessoa: Universitária; CNPq, 1990.

SILVA, Alberto da Costa e. A enxada e a lança: A África antes dos portugueses. Rio de Janeiro: Nova Fronteira; São Paulo: Edusp, 1992.

SLENES, Robert. Na senzala uma flor: as esperanças e recordações na formação da família escrava -Brasil Sudeste, século XIX. Rio de Janeiro: Nova Fronteira, 1999.

THEODORO, Gerson; MORAES, Wallace; GOMES, Flávio. Dos quilombos ao quilombismo: por uma história comparada da luta antirracista no Brasil (Notas para um debate). Revista da Associação Brasileira de Pesquisadores/as Negros/as (ABPN), v. 8, n. 18, nov. 2015 - fev. 2016, $\quad$ p. $215 \quad 238 . \quad$ Disponível em http://abpnrevista.org.br/revista/index.php/revistaabpn1/article/view/49. Acesso em 12 de julho de 2020.

VIDAL, Ademar. Três séculos de escravidão na Paraíba. Estudos Afro-Brasileiros. Recife: FUNDAJ, Editora Massangana, 1988.

Recebido 03/07/2020

Aprovado em 22/07/2020

Revista da ABPN • v. 12, n. Ed. Especial - Caderno Temático: "Africanos, escravizados, libertos biografias, imagens e experiências atlânticas" • agosto de 2020, p. $197-222$ 